\title{
A sand-digging apparatus for rats
}

\author{
PAUL T.-P. WONG, TOM ROACH, and BRUCE OSBORNE \\ Trent University, Peterborough, Ontario, Canada K9J $7 B 8$
}

\begin{abstract}
An apparatus that permits automatic recording of the topography of sand digging was described. Research carried out to evaluate the apparatus indicates that time in sand contact is better correlated with the amount of sand displaced than frequency of contact. Experiment II shows that a sand-andiron-filing mixture has no suppressive effect on sand digging as compared to normal sand.
\end{abstract}

Rats spontaneously dig sand without external reward (e.g., Deutsch, 1960; Rosenzweig, Bennet, \& Diamond, 1972). The same behavior has been observed in mice, although the extent of sand-digging activity can be influenced by food deprivation and reward (Earl, 1957; Fantino \& Cole, 1968). Deermice also learn to press a lever in order to burrow in sand (King \& Weisman, 1964).

The sand-digging apparatus used by previous investigators (Earl, 1957; Stone, 1937) was large and cumbersome, involving three boxes and one tube filled with sand. Typically, rats or mice were required to dig through a tunnel to reach a reward box. The only measure obtainable was the amount of sand dug out over a fixed period of time. This paper describes a simple sand-digging apparatus that is much smaller and can be easily attached to a standard Skinner box. In addition to the measurement of the amount of sand displaced over time, the apparatus provides automatic measures of time spent in contact with the sand as well as the frequency of contact (digging or touching).

\section{EXPERIMENT I}

This experiment was conducted to test the effectiveness of the equipment and to determine the intercorrelation of three measures: amount of sand displaced, time in contact with the sand, and frequency of contact.

\section{Method}

Subjects. Twelve female Holtzman $\mathrm{X}$ light hooded rats, bred in the Trent University animal colony, served as subjects. Half of the subjects were 2 months old, and half were 3 months old at the beginning of the experiment. Two animals were randomly assigned to one of the three groups, with the restriction that each group contain two 2-month-old and two 3-month-old animals. Animals were housed in individual cages with water available. Group 1 was given food on an ad-lib basis (ad-lib); subjects in Group 1 were given $15 \mathrm{mg}$ of Purina lab chow per day (low deprivation); Group 3 were provided $8 \mathrm{~g}$ of lab chow daily (high deprivation).

This study was supported by NRC Grant A8635 awarded to P.T.-P. Wong. We are grateful to Lynn Michele Finnie for collecting the data of Experiment $I$ and to Felen Orr for collecting the data of Experiment II.

Requests for reprints should be addressed to Paul T.-P. Wong, Department of Psychology, Trent University, Peterborough, Ontario, K97 7 B8, Canada.
Apparatus. The sand-digging assembly was attached to one side of a cardboard box, size $23 \times 23 \times 23 \mathrm{~cm}$. The unit consists of a $5 \times 5 \mathrm{~cm}$ platform, a $5 \times 5 \mathrm{~cm}$ back wall, both of $1.2 \mathrm{~cm}$ thick particle board, and a vertical tube mounted on a metal plate attached to the back of the platform. The tube can be lowered or raised to adjust the flow of the sand. Figure 1 depicts the assembly plus two optional features not employed in the present experiment. The first option is a guard, made of Plexiglas or particle board, mounted on the opening side, about $1 \mathrm{~cm}$ above the platform. This addition has the effect of preventing the animal from sitting on the platform as well as slowing down the flow of sand. The second option is a $2.54 \times 2.54 \mathrm{~cm}$ metal plate, screwed to the floor of the platform and placed directly under the tube. One side of the circuit can be connected to this plate instead of to the metal plate that holds the tube, thus improving the sensitivity of unit. The effectiveness of these two optional features has been borne out in subsequent experiments.

The acrylic tube was filled with a mixture of $70 \%$ fine sand and $30 \%$ iron fillings purchased from Fisher Scientific Company, New Jersey. Approximately $5 \mathrm{ml}$ of water per $100 \mathrm{ml}$ of the above mixture was added to increase electrical conductance without adversely affecting the flow properties of the sand. One may also increase the percentage of iron fillings to improve electrical conductance; but this may endanger the health of the animal. Large containers, such as an inverted plastic Javex container can be attached to the acrylic tube to increase the amount of sand available for digging.

A modified "lickometer" circuit detected digging activity. A schematic of the circuit is shown in Figure 1. The floor of the cardboard box was a grounded sheet of aluminum, and the other side of the circuit was connected to the metal plate on the sand dispensing unit. The rat, by standing on the floor and touching the sand, completed the circuit, thus activating two lickometer detector units; these units in turn closed relays. One unit and relay were connected to a Hunter Model 12A Klockounter wired to accumulate the amount of sand-contact time. Each contact incremented a minimum of $.01 \mathrm{sec}$. The second detector and relay were connected with another Klockounter wired to count the number of sand contacts made by the rat.

Procedure. Testing began after both high and low deprivation groups had been deprived for 10 days. Two identical sets of the apparatus were constructed, allowing the rats to be tested in pairs. The boxes were covered with Plexiglas lids; the lids were covered with dark plastic sheets to minimize distractions.

Each rat was tested for $10 \mathrm{~min}$ each day for 5 consecutive days. Half of the subjects in each group were tested in one box; another half in the other box. The order of testing was randomized each day. After testing, the rats were returned to their home cages, and the sand on the floor of each box was collected and weighed. Subjects were provided daily ration one half hour after all testing was completed.

\section{Results and Discussion}

Time scores were converted to common lograithms, 


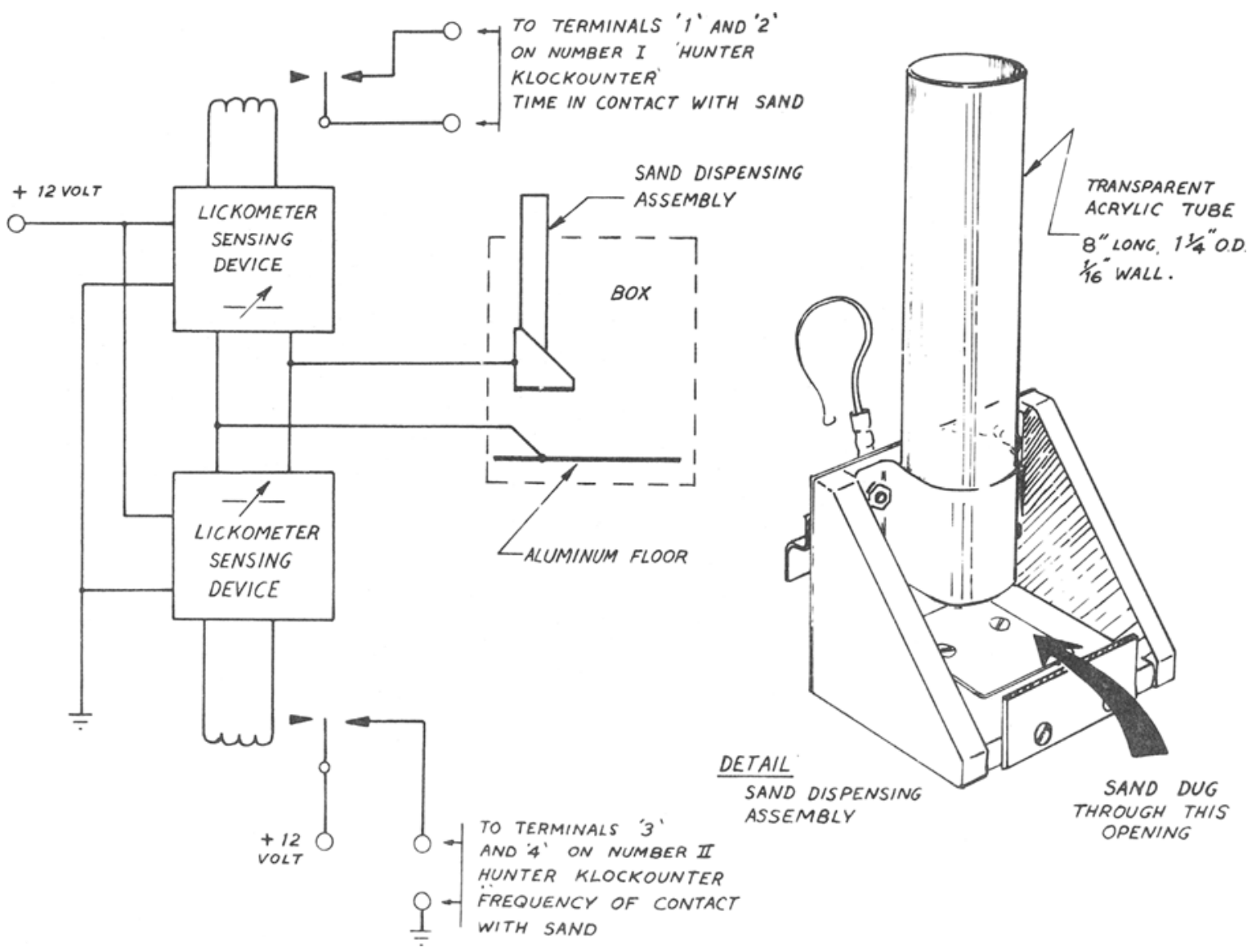

Figure 1. Sand-dispensing assembly and the circuit diagram.

and time and frequency in contact with the mixture were subjected to analysis along with the weight of the sand on the floor of the box.

Statistical analyses showed no significant effects for any measure. Intragroup variability was high. The low capacity of the sand dispenser probably lowered the scores on all three measures for at least the high deprivation group. (A subsequent study with increased sand capacity and a larger $N$ per condition did show significant effects of deprivation'.) Group mean scores did show that for both time and weight measures, sand digging increased with the level of food deprivation. This trend is in accordance with the results reported by Earl (1957) and Fantino and (ole (1968).

Frequency did not prove a sensitive measure because the rat could rest one paw on the sand for a period of time and dig with another paw, thus, the frequency measure of this period would register 1 .

Correlation coefficienrs (Pestson's $r$ ) on scores pooled across days indicated that the relationship between frequency and weight was low (.49). The correlation between time and weight measure was much higher (.72), suggesting that the time measure is a more valid indicator of sand-digging activity.

\section{EXPERIMENT II}

Questions could be raised concerning the use of iron filings in the sand mixture. In Experiment II we investigated if the addition of iron filings and water had an effect different than pure sand.

\section{Method}

Subjects. Six light-hooded rats bred in the Trent University animal colony served as subjects. The animals were approximately 5 months old at the beginning of the experiment and were reduced to $80 \%$ of their predeprivation body weights during the period of testing.

Apparatus. The sand-digging apparatus was made of $2-\mathrm{cm}$ thick particle board, measuring $50 \mathrm{~cm}$ long $x 23.5 \mathrm{~cm}$ wide $x$ $25 \mathrm{~cm}$ high. A partition, made of $1.27 \mathrm{~cm}$ thick plywood was inserted midway, forming two boxes of equal size. At the center of each end wall, a $9 \mathrm{~cm}$ wide $\times 25 \mathrm{~cm}$ high opening was made, leading to a recessed box measuring $9 \mathrm{~cm}$ wide $x 25 \mathrm{~cm}$ high $x$ $6.5 \mathrm{~cm}$ deep. A sand dispensing assembly depicted in Figure 1 was installed in each of the two recessed boxes. A Plexiglas sliding door left an opening $9 \mathrm{~cm}$ wide $\times 8 \mathrm{~cm}$ high above the guard. This arrangement made it virtually impossible for a rat to sit or stand on the sand digging platform.

The floor of cach box was made of metal grids. Two metal trays were placed beneath the grids to collect sand.

The boxes were covered with Plexiglas lids. A funnel was attached to the acrylic tube to increase the sand-holding capacity to approximatcly $2000 \mathrm{~g}$ 
Procedure. All subjects were tested with the sand-iron mixture (Mixture) used in Experiment $I$ and sand containing the same amount of water but no iron filings. Subjects were tested $1 / 2-h$ per day for 4 consecutive days in counterbalanced fashion. During the sessions sand in each funnel was replenished as it emptied.

\section{Results and Discussion}

Since the sand-iron mixture is heavier than sand, the amount of sand dug was measured in millileters. Although rats tended to dig more mixture than sand (794.2 $\mathrm{ml}$ vs. $595.1 \mathrm{ml}$ ), the difference was not statistically significant.

\section{CONCLUSION}

The apparatus described in this paper has been installed in a Skinner box and in a runway in our laboratory to study sand digging, either as an operant or an adjunctive behavior. Rats exhibit sand-digging behavior with this apparatus even though it does not involve burrowing through a tunnel as do various versions of traditional sand-digging apparatus. This apparatus, with slight modification in size, can also be used to study the sand-digging behavior of mice, gerbils, hamsters, and other rodents.

\section{REFERENCES}

Deutsch, J. A. The structural baris of behaulor. University of Chicago Press, 1960, Pp. 52-53.

Earl, R. W. Motivation, performance and extinction. Journal of Comparative and Physiological Psychology, 1957, 50248-251.

Fantino, E., \& Cole, M. Sand-digging in mice: Functional autonomy? Psychonomic Science, 1968, 10, 29-30.

King, J. A., \& Weisman, R. G. Sandi-digging contingent upon bar pressing in deermice (peromyscus). Animal Behavior, 1964, $12,446-450$.

Rosenzweig, M. R., \& Bennet, E. L., \& Diamond, M. C. Brain changes in response to experience. Scientific American, 1972, 226, 22-29.

Stone, C. P. A sand-tube obstruction apparatus. Journal of Genetic Psychology, 1937, 50, 203-206.

\section{NOTE}

1. Wong, P. T.-P. Deprivation levels, sex differences, and sand-digging behaviour in the rat. Manuscript in preparation.

(Received for publication February 22, 1974, revision accepted October $15,1974$. 